\title{
The effects of price bundling on consumer evaluations of product offerings
}

Michael D. J ohnson University of Michigan Business School, 701 Tappan Street, Ann Arbor, Ml 48109-1234, USA

Andreas Herrmann Department of Marketing, J ohannes Gutenberg Universitat Mainz, Saarstrasse 21, D-55099 Mainz, Germany

Hans H. Bauer Lehrstuhl fur ABWL und Marketing II, Universitat Mannheim, Postfach 1034 62, 68131 Mannheim, Germany

\begin{abstract}
The bundling of multiple products or components at a set price has become a popular marketing strategy. Although little is known of how bundled price information should be presented to consumers, mental accounting principles provide guidelines. These principles suggest that more positive evaluations should result from bundling or integrating component prices into a single price and debundling or segregating component discounts into a set of discounts. A study is reported in which consumers were presented an offer for an automobile and then asked to evaluate their satisfaction with the offer, likelihood of recommending, and likelihood of repurchasing the brand. The study supports the predictions as all three evaluations increase when price information is bundled and price discount information is debundled.
\end{abstract}




\section{Introduction}

Price bundling, the practice of combining multiple products or components at a set price, has become a popular marketing strategy (Eppen et al., 1991; Dolan and Simon, 1996). Food and beverage suppliers bundle ready-to-serve meals while computer vendors bundle a central processing unit, a monitor, a printer and software at a single price. Manufacturers of industrial goods, such as machine tools, electronic components and chemical substances, frequently offer their products at a system price in conjunction with an assortment of services. In the service sector, travel companies bundle flights, rent-a-cars, accommodations, and events into a oneprice vacation package. Strategically this bundling activity is designed to benefit the consumer, as through a reduction in transaction costs or combining of complementary products and services to differentiate an offering, and/or reduce a company's own transaction costs (Demsetz, 1968; Dansby and Conrad, 1984).

The psychology of consumer judgment and choice adds a potentially important dimension to price bundling. Research on mental accounting and related framing effects predicts that the integration (bundling) vs. segregation (debundling) of gains and losses for otherwise equivalent prospects influences evaluation and choice (Kahneman and Tversky, 1979, 1984; Thaler, 1985; Thaler and J ohnson, 1990). Specifically, individuals should prefer to integrate losses and segregate gains. Yet the significance of these phenomena for price bundling remains relatively unexplored (Gijsbrechts, 1993; Yadav and Monroe, 1993). Nor is it obvious that the predictions will hold as the effects may depend on task, content, and context variables (Wang, 1996a).

The aim of this paper is to examine whether, and to what degree, the bundling of pricerelated information influences consumer evaluations. The primary contribution of the research is to extend mental accounting principles to the bundling of price-related information. Both prices and price discounts are systematically bundled and debundled. This allows us to contrast relative gains (price discounts) vs. losses (prices). The study includes a no discount condition that allows us to benchmark the effects of bundling vs. a price discount per se. The study also explores the potential moderating effects of consumer experience on mental accounting predictions. After describing price bundling and mental accounting research and developing the research hypotheses, an empirical study is reported in which consumers evaluated automobile offers. The results generally support the predictions of mental accounting in a price bundling context and have important implications for marketing policy.

\section{Price bundling}

Existing price bundling research emphasizes the economic logic of bundling itself. Hanson and Martin (1990; see also Eppen et al., 1991) outline an approach to bundling which jointly optimizes the composition and price of a bundled product. Others have focused on the formation of successful product and service combinations (Bell, 1986; Guiltinan, 1987), such as linking a microcomputer to a long-term maintenance contract to improve the competitive position of a computer supplier. The problems inherent in the implementation of price bundling strategies are also well documented (Prybeck and Alvarez, 1990; Eppen et al., 1991). 
The limited psychological research on bundling focuses more on the evaluation process or mechanism used to evaluate bundled products. Gaeth et al. (1991) demonstrate how evaluations of bundled products are consistent with an averaging model (from Anderson, 1981 information integration theory) whereby component ratings are balanced or averaged into an overall evaluation. Yadav (1994) argues that buyers evaluate product bundles using an anchoring and adjustment model. His research shows that consumers tend to anchor on the more important item in a bundle and adjust their evaluations by taking into account less important items. These two studies are consistent in that anchoring and adjusting is presumed to underlie many of the processing strategies and models reported by decision researchers, including an averaging model (J ohnson and Puto, 1987; Hogarth and Einhorn, 1989). Outside of research on bundling per se, studies have examined how environmental factors influence consumers' acceptability of different price levels. Grewal and Baker (1994) show, for example, how different price levels are more or less acceptable to consumers depending on the environmental context. The authors demonstrate how a product's price is considered more acceptable and leads to higher purchase intensions when considered within the context of a 'high-social' store vs. a 'low-social' store.

These research studies have not, however, explored specifically how the bundling or presentation of price information per se influences consumer evaluations. This limits a seller's ability to optimally present a price bundle to consumers. In a comprehensive review of the pricing literature, Gijsbrechts (1993) points specifically to the lack of research on the psychological aspects of pricing in this area. As Yadav and Monroe lament, "no research has been directed specifically at how sellers should present price information to buyers to promote bundled offers as well as the individual items that comprise the bundle" (Yadav and Monroe, 1993, p. 350). Mental accounting research suggests that bundling should have very different effects on consumer evaluations of product offering depending on the type of price information involved, prices or price discounts.

\section{1. Mental accounting and framing effects}

Principles of mental accounting (Thaler, 1985) and related framing effects (Kahneman and Tversky, 1979) are used here to make specific predictions regarding the bundling and debundling of price-related information. As argued subsequently, a bundled price should result in more positive consumer evaluations than a presentation of individual component prices, while the debundling of price discounts should result in more positive evaluations than a single bundled discount. This prediction is based on the encoding and evaluation of price-related information as relative gains or losses. This gain vs. loss framing is central to the Kahneman and Tversky (1979) prospect theory. Of particular interest is prospect theory's value function, presented in Fig. 1, in which outcomes are framed as positive or negative deviations (gains and losses) from a reference point. In developing our hypotheses and empirical study, we assume that price information is perceived as a relative loss while price discount information is perceived as a relative gain. The value function is concave in the domain of gains and convex in the domain of losses making it consistent with the notion of diminishing positive returns to marginal gains and diminishing negative returns to marginal losses. An addition of $\$ 5$ to a $\$ 10$ gain is thus perceived as larger than an equal addition of $\$ 5$ to a $\$ 100$ gain.

The function predicts, for example, that individuals will generally prefer a sure gain of $\$ 100$ to a lottery in which they have a 50/50 chance of winning $\$ 200$ or nothing. It also predicts 
that individuals will generally avoid a sure loss of $\$ 100$ when the alternative is a $50 / 50$ chance of losing $\$ 200$ or nothing. In this traditional framing effect, people are more likely to be risk averse when prospects are framed as gains and more likely to be risk seeking when like prospects are framed as losses. Because of diminishing returns, people want what is perceived as the larger of the two gains and the smaller of the two losses. The value function is presumed to be steeper for negative deviations from the reference point than for positive deviations which is consistent with the observation that losses weigh more heavily than gains of identical magnitude (Thaler, 1985).

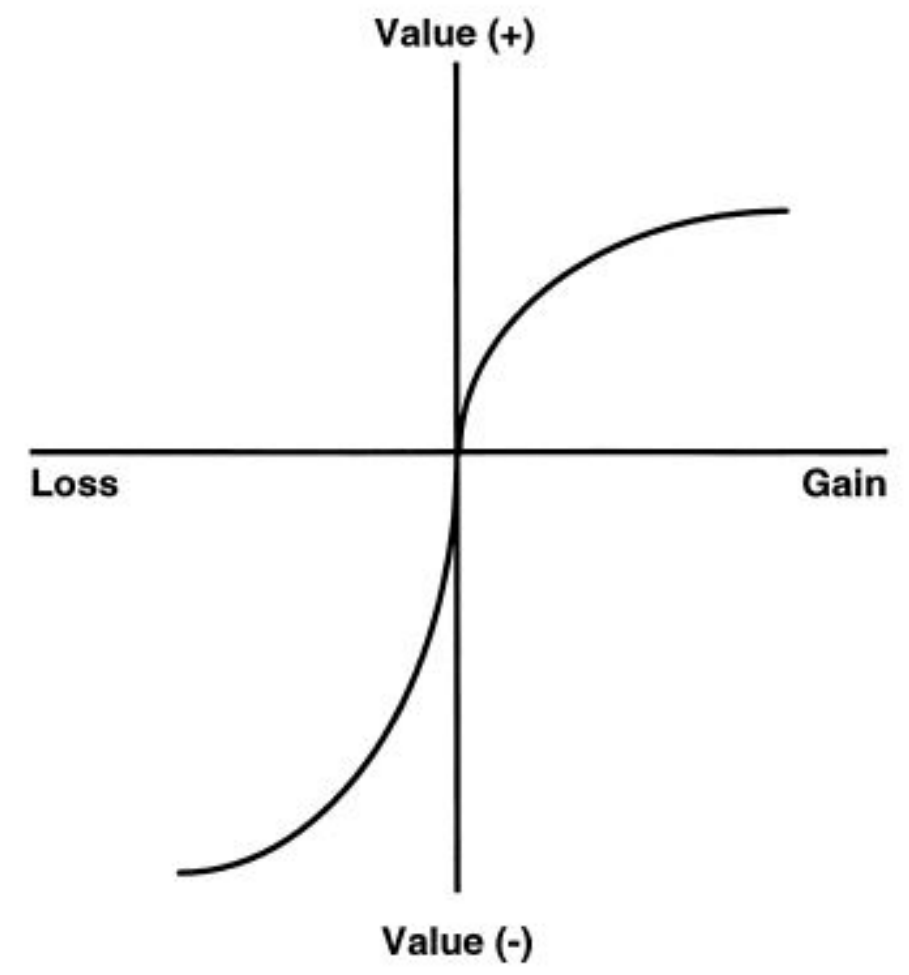

Fig. 1. Prospect theory's value function (from Kahneman and Tversky, 1979).

Stated formally, the concave portion of the value function in Fig. 1 predicts that for any two gains, $x$ and $y$, having values of $v(x)$ and $v(y)$, respectively, the following inequality holds:

$$
[v(x)+v(y)]>[v(x+y)], \text { for all } x, y>0 .
$$

The two gains have a higher value when considered individually than when they are integrated into a total gain. Intuitively, individuals place greater value on receiving several small, separate gains than on receiving one large gain of equal amount. Since the value 
function has a convex shape in the domain of losses, two losses, $-x$ and $-y$, can be described by the following expression:

$$
\begin{aligned}
& {[v(-x)+v(-y)]<[v(-x+-y)],} \\
& \text { for all } x, y>0 .
\end{aligned}
$$
single loss.

Two losses are consequently perceived as lower overall when they are combined into a

Eqs. (1) and (2) form the basis of the arguments of Thaler (1985) as to how consumers mentally account for gains and losses. Eq. (2) predicts that it is advantageous to mentally integrate or bundle multiple losses, such as price information, to minimize the negative effect of that information on consumer evaluations of an offer. This prediction is consistent with the prediction of Nagle and Holden (1995) regarding pricing tactics. Eq. (1) predicts that it is also advantageous to mentally segregate or debundle multiple gains, such as price discounts, to create more positive consumer evaluations.

Clearly, Eqs. (1) and (2) suggest that the bundling of gains and losses has the potential to affect consumer perceptions. Yet there is growing evidence that mental accounting predictions and framing effects depend on a variety of task domain, content, and context variables inherent in evaluation and choice problems (Schneider and Lopes, 1986; Puto, 1987; Bohm and Lind, 1992; Schneider, 1992; Heath et al., 1995; Wang, 1996 a, b). In a consumer context, Heath et al. (1995) found that mental accounting principles are more likely to manifest themselves in the absence of popular percentage-based pricing frames (33\% off). The existence of percentage-based frames decreased respondent tendency toward some mental accounting principles and increased the tendency toward others.

There is also evidence to suggest that mental accounting principles may not hold in a price bundling context. Morwitz et al. (1998) studied the effects of 'partitioned' prices on price perceptions and repurchase intentions. Partitioned prices occur when the price of a single product is divided into two or more mandatory components. The authors presented subjects with a combined price (such as a telephone for $\$ 82.90$, including shipping and handling) or a partitioned price (such as a telephone for $\$ 69.95$ plus a $\$ 12.95$ surcharge for shipping and handling). In contrast to mental accounting principles, the authors found that price perceptions were lower, and repurchase intentions higher, when the price information was partitioned. The explanation for the findings is that consumers often use heuristics when evaluating the partitioned prices. This heuristic processing either leads consumers to focus on the price for the product only and insufficiently adjust their perceptions to take into account the value of the surcharge, or leads them to ignore the surcharge all together. The result is lower perceptions of the cost of the product and higher demand in the form of repurchase likelihood measures.

As these authors warn, partitioned and bundled prices are qualitatively different. Partitioned prices do not provide overall price information to consumers while, in our study, the overall price of the auto is always made available. Nevertheless, the heuristic processing hypothesis provides a natural alternative to mental accounting. Notice that when the heuristic processing argument is extended to include price discount information, it again predicts effects that are the opposite of mental accounting. When price discount information is debundled, heuristic processing suggests that consumers may either insufficiently adjust to take into 
account all of the discounts or ignore some discounts altogether. This should result in more positive evaluations when discount information is bundled rather than debundled.

\subsection{Framing effects and consumer experience}

Our hypotheses are tested using a cross-section of potential repeat customers. The respondents in our study previously owned the automobile in question and were in the market for a replacement vehicle. This is a natural population to target given the high importance placed on consumer loyalty in affecting business performance (J ohnson, 1998). At the same time, these buyers varied significantly with respect to their experience with the product and product category.

Puto (1987) provides a conceptual model to help understand how this variation in experience influences the framing of alternatives. His model posits that individuals enter a judgment or choice situation (such as our study) with an initial frame of reference. This framing is based on existing expectations and objectives derived from the buyer's earlier experience. The individuals are then presented with experimental manipulations that attempt to frame outcomes as gains or losses. Puto hypothesizes, and demonstrates, that the less committed individuals are to their initial, internally generated reference points, and the more likely an externally provided framing manipulation is to affect their decisions. The more commit- ted the individuals are to their initial reference points, the less likely a framing manipulation (or in our case a bundling manipulation) will affect their evaluations and resulting decisions. Puto's model and findings suggest that as consumers gain experience with a product or product category, they are more likely to be committed to existing, internally-based frames of reference when processing decision-relevant information. As a result, they should be less prone to external manipulations such as price bundling.

Puto's study is consistent with the finding that more experienced subjects rely more on internally stored information when making evaluations and decisions (Moore and Lehmann, 1980; Lehmann et al., 1982). It is also consistent with the knowledge-assembly theory of Hayes-Roth (1977). This theory argues that, as individuals learn through accumulated experience, their knowledge of a particular stimulus becomes a more stable and integrated whole. Thus a buyer's accumulated knowledge and experience with a brand and category should affect the stability and strength of any internal frames of reference that buyers use to evaluate options. This should decrease the effectiveness of external sources of information toward affecting the way buyers mentally account for price and price discount information.

This line of reasoning suggests that, as a consumer's experience and knowledge base grows, the proposed mental accounting predictions become either less pronounced or nonexistent. However, there is also a competing hypothesis with respect to experience based on a consumer's motivation to process detailed information. 1 Experienced buyers, who are already predisposed toward a particular brand, may have a preference for external information that integrates price details for them. In contrast, new or less experienced buyers might allocate more effort to the task and prefer as much detail as possible. This would allow the less experienced buyer to come to some balanced evaluation with regard to a product they are less familiar with. As a result, experienced buyers may be even more susceptible to the bundling and debundling of price information than less experienced buyers. 


\subsection{Consumer evaluations: satisfaction, recommendation, and repurchase}

The value function in Fig. 1 embodies a proposed theoretical relationship between objective gains and losses and their equivalent perceived or subjective evaluation. In a marketing context, there are multiple, related dependent variables that constitute a consumer's evaluation of a product or service offering. One is a consumer's evaluation of satisfaction with the offer itself. Two important consequences of a positive evaluation include the likelihood of recommending the offer to others and the likelihood of repurchasing the same brand again in the future. At a molar level, all three measures reflect the output of a positive (vs. negative) evaluation process. The recommendation and repurchase measures are also important from a marketing policy standpoint. Repurchase likelihood is important because of its relationship to profitability (J ohnson, 1998), while word-of-mouth measures (such as likelihood to recommend to others) are important in an automobile context where repurchase cycles are long and customers themselves are an important source of market information.

Applying the mental accounting logic described previously and captured in Eqs. (1) and (2) to these three dependent variables yields the following hypotheses:

H1: Consumer evaluations of an offer increase as component price information is bundled. This includes evaluations of:

a) The perceived satisfaction with an offering.

b) The perceived likelihood of recommending the offering to other people.

c) The perceived likelihood of repurchasing the brand again.

H2: Consumer evaluations of an offer increase as component price discount information is debundled. This includes evaluations of:

a) The perceived satisfaction with an offering.

b) The perceived likelihood of recommending the offering to other people.

c) The perceived likelihood of repurchasing the brand again.

The null hypothesis is that the bundling of price and price discount information has no effect on consumer evaluations because the consumers have developed a frame of reference for evaluating price- related information independent of bundling.

A third hypothesis predicts that more experienced buyers are less likely to exhibit evaluations that are consistent with mental accounting predictions. As argued, more experienced subjects may be more likely to rely on internal knowledge and frames of reference when evaluating the car offers and, as a result, be less sensitive to price bundling manipulations:

H3: The predicted increase (decrease) in consumer evaluations of an offer as component price (price discount) information is bundled is lower for more experienced consumers than for less experienced consumers. This includes evaluations of:

a) The perceived satisfaction with an offering. 
b) The perceived likelihood of recommending the offering to other people.

c) The perceived likelihood of repurchasing the brand again.

An alternative hypothesis predicts just the opposite effect. Because more experienced buyers may be less motivated to process car offer information in detail, they may be more willing to accept the price and price discount bundling as frames of reference when evaluating the offers. They may, therefore, be more likely to follow mental accounting predictions. If we find that hypotheses one and two are supported while consumer experience has no effect on the results, it would suggest that our findings are robust to differences in experience.

\section{Empirical study}

An empirical study was conducted using variations on an automobile offer from a large German manufacturer to test the hypotheses. In each case, previous owners who were in the market for a replacement were contacted by an independent marketing research firm and asked to evaluate an offer. Each offer was for the same base model of automobile with 12 optional extras. The offers varied along three levels of a price bundling factor. For level one, respondents were presented a single bundled price for the basic model and optional extras. For level two, a partially bundled price, composed of separate prices for the base model, interior extras as a package (velvet seat covers, electric windows, air conditioning, radio, on-board computer), exterior extras as a package (metallic paint, aluminum wheels, sun-roof, tow coupling), and safety extras as a package (central locking, anti-theft alarm, passenger airbag), was presented. For level three, respondents were presented a completely debundled price, composed of separate prices for the base model and each of the 12 individual optional extras.

As mentioned in Section 1, an important feature of our design is that it allows us to compare the effects of bundling vs. a discount per se. To accomplish this, the offers also varied along four levels of a price discount factor. First is a no discount condition in which the vehicle price was held constant at DM49,230 Second is a bundled discount amounting to $10 \%$ of the price of the entire vehicle (base model plus optional extras). Because a $10 \%$ price discount is consistent with promotional discounts in the auto- mobile industry, it provides a natural benchmark for evaluating the relative effects of bundling. Third is a partially bundled discount composed of separate $10 \%$ discounts on the base model, interior extras package, exterior extras package, and safety extras package. Fourth is a debundled price discount composed of separate $10 \%$ discounts on the base model as well as each of the 12 optional extras. For all three price discount conditions the price of the vehicle was thus constant at DM44, 307. The result is a 3 (levels price bundling factor) by 4 (levels of price discount factor) experimental design yielding 12 experimental conditions as outlined in Table 1, where the three types of price discount are nested within a discount/no discount manipulation. Table 2 provides details of the price and price discount values (in DM) across experimental conditions.

For example, car offer 1 is characterized by the fact that the optional extras and the basic model form a single package, the list price of which is DM49, 230. Offer 2, on the other hand, is distinguished by partial price bundling, since both the price of the basic model and the prices of the option packages are revealed. Offer 3 differs from the first two offers in that it specifies the price of each individual optional extra, in addition to that of the base model. Offers 4, 5 and 6 can be interpreted in a similar way, except that the car manufacturer grants a 
bundled discount of 10\% (DM4923) on the total list price. Offers 7, 8 and 9 contain a partially debundled price discount, since they indicate the discounts on the basic model

and each of the three option packages. In contrast, offers 10, 11 and 12 show separate price reductions on the base model and on each individual optional extra.

In sum, hypothesis 1 predicts that as price information is progressively bundled, evaluations of offer satisfaction, likelihood of recommending, and likelihood of repurchasing should systematically increase. This is because of the proposed mental integration of multiple losses into a single loss. Hypothesis 2 predicts that as price discount information is progressively debundled, evaluations of offer satisfaction, likelihood of recommending, and likelihood of repurchasing should increase. This is because of the proposed mental segregation of a single gain into multiple gains. Meanwhile, the contrast between the discount and no discount conditions provides a benchmark for evaluating the size of any bundling effects. Hypothesis 3 predicts that the effects posited under hypotheses one and two are less prominent among more experienced car buyers.

Another important consideration in the overall experimental design is that the cognitive effort required to process and evaluate the information in- creases systematically across conditions as both price and price discount information is debundled. This underscores the importance of including both prices and price discounts in the design. If an increase in information processing complexity has some positive or negative main effect on consumer evaluations, it is independent of the relative predictions of the two hypotheses. Consider, for example, that target customers for a particular automobile may have a relatively high need for cognition, in which case complexity is preferred. Alternatively, customers may prefer more concise information, in which case complexity may lower evaluations. According to our hypotheses, however, the more complex, debundled price information should be rated less positively while the more complex, debundled price discount information should be rated more positively. If the hypothesized effects are supported, the results cannot be easily explained by some main effect of information processing complexity or simplicity on the evaluations.

Table 1

Experimental design for price and price discount factors

\begin{tabular}{lllll}
\hline Price factor & Price discount factor & & \\
\cline { 2 - 5 } & List price & $\begin{array}{l}\text { Bundled } \\
\text { discount }\end{array}$ & $\begin{array}{l}\text { Partially bundled } \\
\text { discounts on base } \\
\text { model and optional- } \\
\text { extras packages }\end{array}$ & $\begin{array}{l}\text { Debundled discounts } \\
\text { on base model and } \\
\text { individual optional } \\
\text { extras }\end{array}$ \\
\hline $\begin{array}{l}\text { Prices of base model and individual } \\
\text { optional extras bundled }\end{array}$ & Car offer 1 & Car offer 4 & Car offer 7 & Car offer 10 \\
$\begin{array}{c}\text { Prices of basic model and } \\
\text { individual optional extras } \\
\text { partially bundled }\end{array}$ & Car offer 2 & Car offer 5 & Car offer 8 & Car offer 11 \\
$\begin{array}{c}\text { Prices of basic model and } \\
\text { individual optional extras } \\
\text { debundled }\end{array}$ & Car offer 3 & Car offer 6 & Car offer 9 & Car offer 12 \\
\hline
\end{tabular}

The data for the study was collected during the primary selling season for new cars (September and October) in the Munich area. The respondents were a random selection of mall intercept subjects who were presented an automobile offer and then filled out a written questionnaire. The subjects were screened, however, to include only those respondents who were previous owners of the automobile in question, indicated they were currently in the 
market for a replacement automobile, and indicated they would consider repurchasing the automobile.

A respondent saw the actual car and received a list with the price and price discount values. The car was exactly the same for all respondents while, as described earlier, there were 12 different lists for prices and price discounts. Each of the 12 offers was presented to 30 buyers (total $n=360$ ) who were then asked to give their assessment of the relevant dependent variables on a scale from 1 to 7 . The scale for offer satisfaction ranged from 'not at all satisfied' to 'very satisfied'. The scale for likelihood of recommending ranged from 'I will not recommend at all' to 'I will definitely recommend,' while the scale for likelihood of repurchasing ranged from 'I will not repurchase at all' to 'I will definitely repurchase' (all translated from the original German).

\subsection{Consumer experience index}

Multiple measures related to the consumer's experience with the brand and category in question were also collected as part of the study. Two direct measures of brand experience included the number of years the customer had driven the brand (E1) and the number of cars previously purchased of the brand (E2). Three measures of the consumer's involvement and experience with the category were also collected. These included scale responses (from $1=$ completely disagree to $7=$ completely agree) to the following questions (again translated from German): 'I visit my local dealer regularly to get the latest news on cars' (E3), 'I read car magazines and newspapers with information on cars regularly' (E4), and 'I attend car fairs and dealer events regularly' (E5). A principle components analysis of these five measures was conducted to explore their dimensionality. The first principle component accounted for $55 \%$ of the variation among the measures and was the only component with an Eigen value greater than one (2.75). The component loadings were $0.673,0.818,0.770,0.853$ and 0.551 for measures E1 through E5, respectively. Thus the two highest loadings are for the 'number of 
cars purchased of the brand' and the 'degree to which the consumer reads about cars on a regular basis'. Given the relative unidimensionality of the measures, we used the component weights from the first principle component to construct a weighted average of the raw experience scores. This experience index serves as a covariate in our analysis to test hypothesis 3.

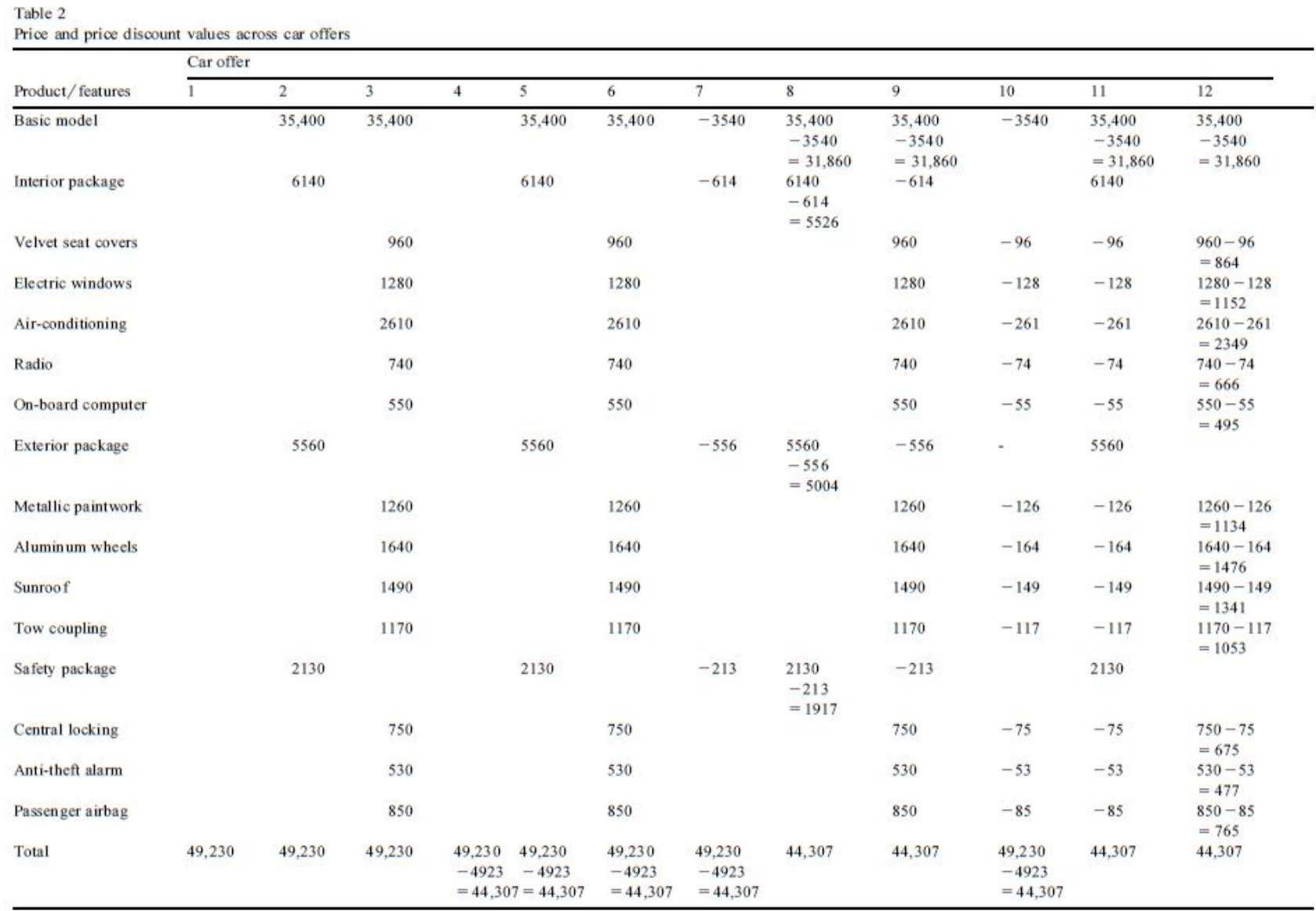

\section{Results}

Univariate analysis of variance ANOVA) models were used to test all three hypotheses for each of the dependent variables. The cell means across various levels of the price and price discount factors are presented in Table 3. Fig. 2 illustrates the results using an average of the satisfaction, likelihood of recommending, and likelihood of repurchasing measures.

Hypothesis 1 predicts that all three evaluations should increase as component price information is progressively bundled. The results in Fig. 2 show the predicted increase in evaluations with price bundling. Using an average of the three dependent variables, evaluations increased from 4.10 to 4.32 to 4.50 for the debundled, partially bundled, and bundled price factor conditions. The ANOVA results, presented in Table 4, reveal that all three dependent variables increase significantly as the price information is bundled. Student-Newman-Keuls (SNK) tests of differences in means were conducted for each of the three dependent measures to examine differences across price bundling levels. For the satisfaction evaluations, there is a 
significant $(p<0.05)$ difference between the debundled price conditions and the partially bundled and bundled price conditions. There is no difference between the partially bundled and bundled price conditions themselves. Regarding likelihood of recommending, there is a significant difference between the debundled and bundled price conditions only $(p<0.05)$. Likelihood of repurchasing is significantly greater for the bundled price conditions compared to both the partially bundled and debundled conditions $(p<0.05)$. Likelihood of re-purchasing is not significantly different for the partially bundled and debundled price conditions themselves. Overall these results support hypothesis 1 ; the bundling of price information increases consumer evaluations which is consistent with mental accounting principles. Our respondents preferred integrated losses to segregated losses.

Hypothesis 2 predicts that evaluations should also increase as price discount information is progressively debundled. The results in Fig. 2 (and Table 3) reveal an increase in the evaluations as price discount information is debundled. The average of the three evaluation

Table 3

Cell means across levels of price and price discount factors

\begin{tabular}{|c|c|c|c|c|c|c|c|c|c|c|c|c|c|c|c|}
\hline \multirow{3}{*}{$\begin{array}{l}\text { Price factor } \\
\text { Bundled }\end{array}$} & \multicolumn{12}{|c|}{ Price discount factor } & \multirow{2}{*}{\multicolumn{3}{|c|}{ Averages }} \\
\hline & \multicolumn{3}{|c|}{ No discount } & \multicolumn{3}{|c|}{ Bundled discount } & \multicolumn{3}{|c|}{$\begin{array}{l}\text { Partially bundled } \\
\text { discount }\end{array}$} & \multicolumn{3}{|c|}{ Debundled discount } & & & \\
\hline & $3.533^{\mathrm{a}}$ & $3.500^{b}$ & $3.933^{c}$ & 4.267 & 4.400 & 4.533 & 4.133 & 4.300 & 4.333 & 5.700 & 5.800 & 5.533 & 4.408 & 4.500 & 4.583 \\
\hline $\begin{array}{l}\text { Partially } \\
\text { bundled }\end{array}$ & 2.933 & 2.933 & 3.500 & 4.233 & 4.367 & 3.800 & 4.800 & 4.467 & 4.733 & 5.500 & 5.467 & 5.100 & 4.367 & 4.309 & 4.283 \\
\hline Debundled & 3.000 & 2.767 & 3.300 & 4.200 & 4.233 & 4.300 & 4.233 & 4.567 & 4.233 & 4.700 & 5.000 & 4.700 & 4.033 & 4.142 & 4.133 \\
\hline Averages & 3.155 & 3.067 & 3.578 & 4.233 & 4.333 & 4.211 & 4.389 & 4.445 & 4.433 & 5.300 & 5.422 & 5.111 & 4.269 & 4.317 & 4.333 \\
\hline
\end{tabular}

${ }^{a}$ Satisfaction with offer.

${ }^{\mathrm{b}}$ Likelihood of recommending.

'Likelihood of repurchasing.

measures increases from 4.26 to 4.42 to 5.28 for the bundled discount, partially bundled discount, and debundled discount conditions. Although the ANOVA result support significant results for the price discount factor in each case (see Table 4), this does not provide a direct test of the hypothesis. This is because the no discount condition, where the average evaluation is 3.27, is included in the analyses. Testing hypothesis 2 requires a hierarchical analysis in which the discount vs. no discount conditions are first contrasted and then contrasts are made among the three nested levels of price discount bundling. The discount vs. no discount contrast of means (level one vs. levels two through four) is highly significant $(p<0.001)$ for each of the three dependent variables: offer satisfaction and likelihood of recommending and repurchasing. Moreover, all three dependent variables increase significantly $(p<0.05)$ as price discount information is progressively debundled.

An SNK test of differences in means for each dependent variable was also conducted for the price discount factor. Consistent with our hierarchical analysis, these results show that when compared to the price discount conditions, the no discount condition results in significantly lower evaluations for satisfaction, likelihood of recommending, and likelihood of repurchasing (all $p<0.05$ or greater).

Among the price discount conditions themselves, the pattern of results was identical for the satisfaction, likelihood of recommending, and likelihood of repurchasing variables. In each 
case, the completely debundled price discount conditions showed significantly higher $(p<0.05)$ evaluations than either the partially bundled or bundled discounts while there were no significant differences between the partially bundled and bundled discounts. Thus the results are driven primarily by the completely debundled discount condition.

The results generally support hypothesis 2; the debundling of price discount information increases consumer evaluations which is again consistent with mental accounting principles. Our respondents preferred segregated gains to integrated gains. One unexpected finding,

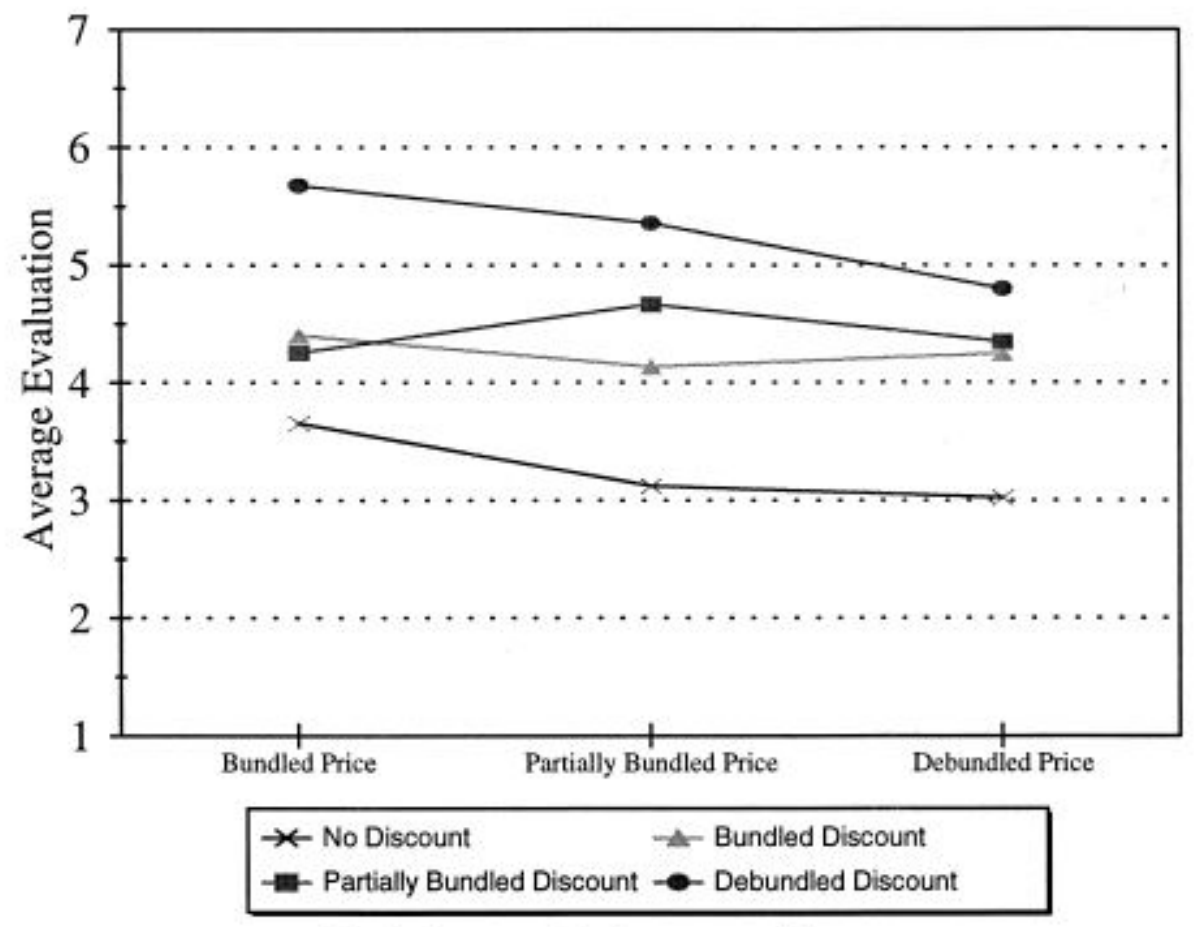

Fig. 2. Average evaluation across conditions.

Table 4

ANOVA-based univariate tests of significance

\begin{tabular}{llclllll}
\hline Factor & Variable & $\begin{array}{l}\text { Between groups } \\
\text { sum of squares }\end{array}$ & $\begin{array}{l}\text { Within groups } \\
\text { sum of squares }\end{array}$ & $\begin{array}{l}\text { Between groups } \\
\text { mean square }\end{array}$ & $\begin{array}{l}\text { Within groups } \\
\text { mean square }\end{array}$ & F-statistic & Significance \\
\hline Price & Satisfaction & 10.139 & 479.100 & 5.069 & 1.377 & 3.682 & 0.026 \\
& Willingness to Recommend & 7.717 & 393.667 & 3.858 & 1.131 & 3.411 & 0.034 \\
& Repurchase Intention & 12.600 & 446.600 & 6.300 & 1.283 & 4.909 & 0.008 \\
Price & Satisfaction & 208.653 & 479.100 & 69.551 & 1.377 & 50.519 & 0.000 \\
Discount & Willingness to Recommend & 252.122 & 393.667 & 84.041 & 1.131 & 74.292 & 0.000 \\
& Repurchase Intention & 108.067 & 446.600 & 36.022 & 1.283 & 28.069 & 0.000 \\
Interaction & Satisfaction & 20.972 & 479.100 & 3.495 & 1.377 & 2.539 & 0.020 \\
& Willingness to Recommend & 12.394 & 393.667 & 2.066 & 1.131 & 1.826 & 0.093 \\
& Repurchase Intention & 16.733 & 446.600 & 2.789 & 1.283 & 2.173 & 0.045 \\
\hline
\end{tabular}

however, was a significant interaction between the price and price discount factors. The interaction is more significant in the case of the satisfaction and repurchase intention measures $(p<0.05)$ than for willingness to recommend $(p<0.10)$. As shown in Fig. 2 , unexpectedly low evaluations for car offer 7 (bundled price with partially bundled discounts. help explain the observed interaction. One possibility here is that car offer 7, and to some degree car offer 10 
(bundled price with debundled discounts), are somewhat unrealistic to consumers. Although they are adjacent conditions in the experimental design, they may create very different perceptions. For offer 10, once the bundled price is presented, the debundled discounts may create a perception that one has the freedom to choose among specific options, such as choosing a radio but not an on-board computer. For offer 7, where the discounts are partially bundled, the perception may be that the customer only has the freedom to choose or not choose a complete package of options thus lowering evaluations in this condition. This explanation is consistent with the observation that the interaction is less significant for likelihood of recommending. If some consumers perceived constraints on their 'freedom of choice' in this condition, this explanation should mainly influence subjects' own preferences and less so their recommendations to others.

Recall that the inclusion of discount vs. no dis- count information in the experimental design pro- vides a benchmark as to the size of these effects. Notice that the difference in average offer satisfaction of 1.078 between the no discount condition (3.155) and the bundled discount condition (4.233) is approximately equal to the difference of 1.067 between the bundled discount (4.233) and debundled discount conditions (5.300; see bottom row of Table 3). The marketing policy implications are startling. J ust how our price discount information was presented had approximately the same impact as a discount of $10 \%$ on the list price. In contrast, the difference in satisfaction evaluations between the bundled and debundled price conditions of 0.375 (i.e., 4.408-4.033) was smaller than either of the two effects.

One explanation for the difference in effect sizes between prices and price discounts centers on the reference points used to evaluate the information. The price discounts are very naturally framed as gains relative to the listed prices. The presumption that price information is itself framed as a loss relative to one's current asset position is more tenuous. Consider that our respondents were all potential repeat customers in the market for an automobile. Their actual reference point for evaluating price information may have been some amount they budgeted or expected to pay for the vehicle or the amount paid in the past. Some respondents may have framed the price information as a smaller loss, or even a relative gain, thus mitigating the predicted framing effect. Nevertheless, the price information was perceived as enough of a cost or loss to support mental accounting principles.

Hypothesis 3 predicts that consumer experience moderates the observed mental accounting results. Specifically, the results should be more pronounced among less experienced vs. more experienced consumers. The experience index described earlier was added to the ANOVA models as a covariate. Hypothesis 3 predicts a significant moderating effect or interaction involving experience and the two bundling factors. These models completely replicate the sup- port for hypotheses one and two. However, the experience index had no significant main effects on the three dependent variables. The two- and three-way interactions involving experience and the bundling manipulations also failed to approach significance. Thus hypothesis 3 is rejected. The alternative hypothesis (that more experienced buyers are more prone to mental accounting predictions) is also rejected. The demonstrated support for hypotheses one and two is thus quite robust to differences in experience among the respondents.

\section{Summary and implications}


Bundling research to date has focused on the economic basis and implications of a bundling strategy. Less attention has been paid to the psychological processing of bundled or debundled price information. Yet the growing literature on mental accounting and framing effects provides explicit pre- dictions as to how consumers evaluate gains and losses and, as a result, how price information should be bundled or debundled. Mental accounting principles suggest that consumers prefer to integrate losses, in the form of price information, into a single bundled price. These same principles suggest that consumers prefer to segregate gains, in the form of price discount information, into a series of debundled discounts. Using an automobile context in which consumers were asked to evaluate a particular vehicle offer, these mental accounting predictions were generally supported.

Primarily our empirical results extend mental accounting effects to a price bundling context. The predictions occurred for customers who previously owned the automobile in question and were considering repurchasing the product. Our results suggest that when a company bundles items for sale, price information should be integrated into a package price. In contrast, price discount information should specify separate discounts on each of the items that make up the bundle. In our case, this practice systematically increased not only the consumers' satisfaction with the presented offer, but their likelihood of recommending and repurchasing the brand as well. The observed interaction between the price and price discount factors was not expected. While the bundling of price information resulted in more positive evaluations, the increases were concentrated in the no discount and debundled discount conditions. As discussed previously, differences in consumer perceptions of their ability to choose options may be driving these results.

A strength of the experimental design used to test our bundling hypotheses is that it was balanced with respect to the complexity of the information presented in the various offers. Debundling both the price and price discount information into a set of component prices or discounts necessitates making the offers more complex. Yet in the case of price information, the more complex offers were evaluated less positively, while in the case of price discount information, the more complex offers were evaluated more positively. Thus differences in offer complexity cannot explain the pattern of results. However, the complexity of the consumers actual processing was not directly measured.

The study used three related dependent variables that are important from a marketing policy stand- point. Offer satisfaction captures a consumer's overall evaluation of an offer, which should impact choice behavior. Increased likelihood of recommending and repurchasing are natural consequences of a positive offer evaluation. Likelihood of repurchasing is important because of the economics of customer retention; it is more profitable to keep customers than to constantly replace them. Likelihood of recommending is important because, in the automotive industry where repurchase cycles are measured in years, consumers are themselves an important source of market information.

It is interesting that the addition of an experience index to our analysis revealed no significant differences for experience and no significant interactions involving experience and our bundling manipulations. Our results appear quite robust to differences in experience among our respondents. Our study does, however, fall short of studying actual purchase decisions and whether or not mental accounting affects these decisions. The question remains as to whether the effects will hold in the face of the significant monetary sacrifice involved in actually buying a car as opposed to just evaluating an offer. The size of the bundling effects, compared to the price discount per se, may be a function of the subjects' motivation to process information. In 
our experimental context, which involved judgments rather than choices, lower motivation may have caused the consumers not to consider the alternatives carefully. In an actual choice, a motivated and careful examination of the offers may result in more equal evaluations of the monetary sacrifice involved across the three price and three price discount conditions. Thus, one natural direction for future research is to study actual purchase decisions.

Another direction for future research is to examine the influence of a variety of potentially moderating effects on price bundling. Two potential moderating factors described earlier are a consumer's need for cognition vs. their preference for summary information. Following Morwitz et al. (1998), the manner in which the information is presented and the consumer's affect for a given brand may also moderate how buyers process price information. Heath et al. (1995) suggests specifically that replacing actual prices and price discounts with percentage-based amounts may alter the effects of bundling. Finally, researchers interested in modeling optimal price levels for product introductions (see Bayus, 1994) should benefit from explicitly incorporating the psychological effects of bundling into more economic-based models. Given the potential for bundling to systematically affect consumer evaluations of product offerings, it will be important both theoretically and pragmatically to explore the boundaries of our findings. 


\section{References}

Anderson, N., 1981. Foundations of Information Integration Theory. Academic Press, New York.

Bayus, B.L., 1994. Optimal pricing and product development polices for new consumer durables. International J ournal of Research in Marketing 11, 249-259.

Bell, M.L., 1986. Some strategic implications of a matrix approach to the classification of marketing goods and services. Journal of the Academy of Marketing Science 14, 13-20.

Bohm, P., Lind, H., 1992. A note of the robustness of a classical framing result. Journal of Economic Psychology 13, 355-361.

Dansby, R.E., Conrad, C., 1984. Commodity bundling. American Economic Review 74, 377-381.

Demsetz, H., 1968. The cost of transacting. Quarterly J ournal of Economics 82, 33-53.

Dolan, R.J ., Simon, H., 1996. Power Pricing: How Managing Price Transforms the Bottom Line. The Free Press, New York.

Eppen, G.D., Hanson, W.A., Martin, K.R., 1991. Bundling-new products, new markets, low risk. Sloan Management Review 23, 7-14.

Gaeth, G.J ., Levin, I.P., Chakraborty, G., Levin, A.M., 1991. Consumer evaluation of multiproduct bundles: an information integration analysis. Marketing Letters 2, 47-57.

Gijsbrechts, E., 1993. Prices and pricing research in consumer marketing: some recent developments. International J ournal of Research in Marketing 10, 115-151.

Grewal, D., Baker, J., 1994. Do retail store environmental factors affect consumers' price acceptability? An empirical examination. International J ournal of Research in Marketing $11,107-115$.

Guiltinan, G.A., 1987. The price bundling of services: a normative framework. Journal of Marketing 51, 74-85.

Hanson, W.A., Martin, K.R., 1990. Optimal bundle pricing. Management Science 36, 155-174.

Hayes-Roth, B., 1977. Evaluation of cognitive structures and processes. Psychological Review $84,260-278$.

Heath, T.B., Chatterjee, S., France, K.R., 1995. Mental accounting and changes in price: the frame dependence of reference dependence. J ournal of Consumer Research 22, 90-97.

Hogarth, R.M., Einhorn, H.J ., 1989. Order effects in belief updating: the believe adjustment model. Working paper, Center for Decision Research, University of Chicago.

J ohnson, M.D., 1998. Customer Orientation and Market Action. Prentice-Hall, Upper Saddle River, NJ .

J ohnson, M.D., Puto, C.P., 1987. A review of consumer judgment and choice. In: Houston, M.J. ŽEd., Review of Marketing. American Marketing Association, Chicago, IL, pp. 236-292.

Kahneman, D., Tversky, A., 1979. Prospect theory: an analysis of decision under risk. Econometrica 47, 263-291.

Kahneman, D., Tversky, A., 1984. Choices, values, and frames. American Psychologist 39, 341350. 
Lehmann, D.R., Moore, W.L., Elrod, T., 1982. The development of distinct choice process segments over time: a stochastic modeling approach. J ournal of Marketing 46, 48-59.

Moore, W.L., Lehmann, D.R., 1980. Individual differences in search behavior for a nondurable. J ournal of Consumer Research 7, 296-307.

Morwitz, V.G., Greenleaf, E.A., J ohnson, E.J., 1998. Divide and prosper: consumers' reactions to partitioned prices. Journal of Marketing Research 35, 453-463.

Nagle, T.T., Holden, R.K., 1995. The Strategy and Tactics of Pricing, 2nd edn. Prentice-Hall, Englewood Cliffs, NJ.

Prybeck, F., Alvarez, F., 1990. How to price for successful product bundling. Journal of Pricing Management 1, 5-18, Part 1.

Puto, C.P., 1987. The framing of buying decisions. Journal of Consumer Research 14, 301-315.

Schneider, S.L., 1992. Framing and conflict: aspiration Level contingency, the status quo, and current theories of risky choice. J ournal of Experimental Psychology: Learning, Memory, and Cognition 18, 1040-1057.

Schneider, S.L., Lopes, L.L., 1986. Reflection in preferences under risk: who and when may suggest why. Journal of Experimental Psychology: Human Perception and Performance $12,535-548$.

Thaler, R., 1985. Mental accounting and consumer choice. Marketing Science 3, 199-214.

Thaler, R., J ohnson, E.J ., 1990. Gambling with the house money and trying to break even: the effects of prior outcomes on risky choice. Management Science 36, 643-660.

Wang, X.T., 1996a. Framing effects: dynamics and task domains. Organizational Behavior and Human Decision Processes 68, 145- 157.

Wang, X.T., 1996b. Domain-specific rationality in human choices: violations of utility axioms and social contexts. Cognition 60, 31-63.

Yadav, M.S., 1994. How buyers evaluate product bundles: a model of anchoring and adjustment. Journal of Consumer Research 21, 342-353.

Yadav, M.S., Monroe, K.B., 1993. How buyers perceive savings in a bundle price: an examination of a bundle's transaction value. J ournal of Marketing Research 30, 350358. 